\title{
COMPARING GIBBS ENERGY RELATIONSHIPS FOR AMMONIA VOLATILIZATIONS FROM AGRICULTURAL SOILS FOR POTATO PRODUCTION
}

\author{
${ }^{1}$ Guodong Liu, ${ }^{2}$ Yuncong Li and ${ }^{3}$ Ashok Alva \\ ${ }^{1}$ Horticultural Sciences Department, \\ Institute of Agriculture and Food Sciences, University of Florida, Gainesville, FL 32611, USA \\ ${ }^{2}$ Soil and Water Science Department, Tropical Research and Education Center, \\ Institute of Agriculture and Food Sciences, University of Florida, Homestead, FL 33031, USA \\ ${ }^{3}$ Department of Agriculture, Agricultural Research Service, Prosser, WA 99350, USA
}

Received 2013-07-19; Revised 2013-08-07; Accepted 2013-09-01

\begin{abstract}
Soil drought, that can be enhanced by global warming increases ammonia $\left(\mathrm{NH}_{3}\right)$ volatilization. This laboratory study was conducted with two soils: Krome Gravelly Loam (KGL) from Florida and Warden Silt Loam (WSL) from Washington State and two fertilizers: Ammonium sulfate $\left[\left(\mathrm{NH}_{4}\right)_{2} \mathrm{SO}_{4}\right]$ or ammonium nitrate $\left(\mathrm{NH}_{4} \mathrm{NO}_{3}\right)$. Two water regimes including 20 and $80 \%$ Field Capacity (FC) were used at $20^{\circ} \mathrm{C}$ which is the average temperature in the potato growing season in Washington State. The data demonstrated that variation in $\mathrm{NH}_{3}$ volatilization subject to different soil water regimes can be explained by changes in Gibbs free energy of Nitrogen $(\mathrm{N})$ fertilization in soils with varying water contents. The absolute values of Gibbs free energy of $\left(\mathrm{NH}_{4}\right)_{2} \mathrm{SO}_{4}$ or $\mathrm{NH}_{4} \mathrm{NO}_{3}$ applied to soil at $20 \% \mathrm{FC}$ soil water regime were 5 -fold greater than at $80 \%$ FC. Accordingly, the equilibrium constant $(\mathrm{K})$ of deprotonation of ammonium ions in soil solutions at $20 \% \mathrm{FC}$ was 3,000- or 50-fold greater than that at $80 \% \mathrm{FC}$ for $\left(\mathrm{NH}_{4}\right)_{2} \mathrm{SO}_{4}$ or $\mathrm{NH}_{4} \mathrm{NO}_{3}$, respectively. Nitrogen loss via $\mathrm{NH}_{3}$ volatilization was 4-to 7 -fold greater at $20 \% \mathrm{FC}$ than that at $80 \% \mathrm{FC}$. This study suggests potential acceleration of $\mathrm{NH}_{3}$ volatilization from soils under drought. Therefore, optimal water management is critical to mitigate $\mathrm{NH}_{3}$ volatilization from agricultural soils.
\end{abstract}

Keywords: Ammonia Emission, Soil Moisture, Gibbs Free Energy, Water Management

\section{INTRODUCTION}

The global ammonia $\left(\mathrm{NH}_{3}\right)$ volatilization from Nitrogen (N) fertilizers routinely used for crop production is estimated to be 11 million $\mathrm{t} \mathrm{N}$ per year ( $\mathrm{Tg} \mathrm{N} / \mathrm{yr}$ ), which is about one seventh of the nitrogen (N) fertilizers used (FAO/IFA, 2001). While $\mathrm{NH}_{3}$ is not regarded as a greenhouse gas, it can affect global warming considerably by being oxidized to nitrous oxide $\left(\mathrm{N}_{2} \mathrm{O}\right)$ or reacting with nitric and sulfuric acids in the atmosphere to form secondary aerosols (Barthelmie and Pryor, 1998; Turner et al., 2010). Dentener and Crutzen (1994) estimated $3 \mathrm{Mg} \mathrm{N} / \mathrm{yr}$ of the globally emitted $\mathrm{NH}_{3}$ can be oxidized by $\mathrm{OH}$ radicals and $\mathrm{NO}_{2}$ (Finlayson-Pitts and Pitts, 2000). A fraction of the oxidized $\mathrm{NH}_{3}$ is transformed to Nitrous Oxide $\left(\mathrm{N}_{2} \mathrm{O}\right)$, a very powerful greenhouse gas and this process accounts for up to $5 \%$ of the global $\mathrm{N}_{2} \mathrm{O}$ emission (Ferm, 1998). After deposition on land surface and water bodies, $\mathrm{NH}_{3}$ acts as a secondary source of $\mathrm{N}_{2} \mathrm{O}$ which contributes to ozone depletion (Martikainen, 1985; Mosier et al., 1998). As a potent greenhouse gas, $\mathrm{N}_{2} \mathrm{O}$ is approximately 310 -fold powerful than $\mathrm{CO}_{2}$ in trapping heat in the atmosphere (Finlayson-Pitts and Pitts, 2000; IPCC, 1996). Thus, $\mathrm{NH}_{3}$ emitted from agricultural soils contributes to global warming.

Corresponding Author: Guodong Liu, Horticultural Sciences Department, Institute of Agriculture and Food Sciences, University of Florida, Fifield Hall, Gainesville, FL 32611, USA Tel: 352-273-4814 Fax: 352-846-0909 
Global warming causes not only climate change but also soil drought. Temperature increase of $1 \%\left(0.32^{\circ} \mathrm{C}\right)$ can increase evapotranspiration by $15 \mathrm{~mm}$ (Goyal, 2004). Evapotranspiration, in turn, can worsen soil drought if the irrigation rate is not adjusted to compensate for the increased loss of moisture. There is evidence that the progression of anthropogenic global warming is accompanied by increased risk of drought, since rising temperature increases the rate of drying (Dai et al., 2004). An increase in either temperature or decrease in soil moisture content significantly accelerates $\mathrm{NH}_{3}$ volatilization from fertilized soils. Soil drought from 80 to $20 \%$ Field Capacity (FC) of soil moisture enhances $\mathrm{NH}_{3}$ volatilization rate by 113 fold (Liu et al., 2007a); while high temperature from 20 to $29^{\circ} \mathrm{C}$ increases the $\mathrm{NH}_{3}$ volatilization rate by 10 fold (Liu et al., 2007b). These increases suggest that $\mathrm{NH}_{3}$ volatilization induced by soil drought impacts global warming and vice versa.

Ammonia volatilization entails a series of steps including a chemical reaction. The spontaneity of each of these steps is determined by the Gibbs free energy according to the second law of thermodynamics. However, no published literature is available for describing the effects of changes in Gibbs free energy on either $\mathrm{NH}_{3}$ volatilization or on the acceleration of $\mathrm{NH}_{3}$ volatilization by soil drought. Therefore, understanding of the relationship between Gibbs free energy and $\mathrm{NH}_{3}$ volatilization is too limited to enable effective control of $\mathrm{NH}_{3}$ volatilization from crop production. Our experimental evidence presented on a mechanism whereby soil drought enhances $\mathrm{NH}_{3}$ volatilization controlled by Gibbs free energy. This mechanism provides clues to alleviate $\mathrm{NH}_{3}$ volatilization from fertilized by improved water management, which minimizes the negative Gibbs free energy of the deprotonation of $\mathrm{NH}_{4}^{+}$ ions and in turn minimize $\mathrm{NH}_{3}$ volatilization.

The objectives of this study were to: (1) quantify Gibbs free energy for $\mathrm{NH}_{3}$ volatilization in two different soils and (2) assess Gibbs free energy in each step of $\mathrm{NH}_{3}$ volatilization from the fertilized soils.

\section{MATERIALS AND METHODS}

\subsection{Measurement of $\mathrm{NH}_{3}$ Volatilization}

Three hundred $g$ dry soil of either Krome Gravelly Loam (KGL) collected from Florida or Warden Silt Loam (WSL) from Washington State was placed in an incubation bottle $(500 \mathrm{~mL}$ in size). The surface area of the soil in the bottle was $\sim 60 \mathrm{~cm}^{2}$. The soil water content was adjusted to either 20 or $80 \%$ of Field Capacity (FC). The percentage of water in the KGL and WSL soils ( $/ / m$ based on oven dry soils) was 8.4 and $6.7 \%$ for $20 \%$ FC and 33.4 and $26.0 \%$ for $80 \%$ FC, respectively. One ml of $\mathrm{N}$ solution consisting of an aqueous solution of either $\left(\mathrm{NH}_{4}\right)_{2} \mathrm{SO}_{4}$ or $\mathrm{NH}_{4} \mathrm{NO}_{3}$ was uniformly applied on the soil surface with a micropipette. The amount of $\mathrm{N}$ applied was $45 \mathrm{mg} \mathrm{N}$ per bottle, equivalent to $75 \mathrm{~kg}$ $\mathrm{ha}^{-1}$ based on the surface area. A treatment with only deionized water (no N) was included as a control to measure the $\mathrm{NH}_{3}$ volatilization from the soils. Thus, this experiment consisted of two soils $\times$ three $\mathrm{N}$ sources (two $\mathrm{N}$ fertilizers plus blank control) $\times$ two water regimes $\times$ three replications which required 36 incubation bottles. Each incubation bottle was placed in a sealed plastic storage bag $(23 \times 30 \mathrm{~cm})$ and maintained at $20^{\circ} \mathrm{C}$ in an incubator (Precision Incubator, 6DM, THELCO $^{\circledR}$ High Performance Incubators, Precision, Ottawa, Canada). Ammonia volatilization was measured on 1, 3, 7, 14 and 28 days after incubation. A sponge with trapping solution was sampled at each sampling period and a new sponge (with trapping solution) was placed to trap emitted $\mathrm{NH}_{3}$ for the subsequent sampling period (Liu et al., 2007a; 2007b).

\subsection{Calculation of Gibbs Free Energy}

Because $\mathrm{NH}_{3}$ volatilization involves three steps: Step 1, dissolution of the applied ammonium fertilizer compound; step 2, deprotonation of $\mathrm{NH}_{4}^{+}$ions; and step 3, transformation of aqueous $\mathrm{NH}_{3}$ into gaseous $\mathrm{NH}_{3}$. In the soil solution, the relative stability of the chemical system, i.e., the tendency of the system to react or change is determined by the Gibbs free energy or simply free energy, quantity derived from the relationships between heat and work in thermodynamics of $\mathrm{NH}_{3}$ volatilization. Systems change toward minimum free energy. Equation (1) is one form of Gibbs fundamental equation:

$\mathrm{G}=\mathrm{H}-\mathrm{TS}$

where, $\mathrm{G}=$ the Gibbs free energy $(\mathrm{kJ}) ; \mathrm{H}=$ the enthalpy $(\mathrm{kJ}) ; \mathrm{T}=$ the absolute temperature $\left({ }^{\circ} \mathrm{K}\right)$; and $\mathrm{S}=$ the entropy $\left(\mathrm{kJ}^{\circ} \mathrm{K}^{-1}\right)$. For each of the above three chemical steps in soil solution, Equation (1) can be rewritten in Equation (2):

$\Delta \mathrm{G}=\mathrm{G}_{\text {products }}-\mathrm{G}_{\text {reactants }}=\Delta \mathrm{H}-\mathrm{T} \Delta \mathrm{S}$

where, $\Delta \mathrm{G}=$ the difference in the Gibbs free energy between products $\left(\mathrm{G}_{\text {products }}\right)$ and reactants $\left(\mathrm{G}_{\text {reactants }}\right)$ in the chemical system. $\Delta \mathrm{H}$ and $\Delta \mathrm{S}=$ the differences in enthalpy and entropy between the products and reactants, 
respectively. Equation (2) predicts the spontaneity of the steps involved in $\mathrm{NH}_{3}$ volatilization:

- $\Delta \mathrm{G}<0$ natural tendency for process to occur (spontaneous)

- $\Delta \mathrm{G}=0$ neither the forward nor the reverse process prevails (equilibrium)

- $\Delta \mathrm{G}>0$ no natural tendency for process to occur (nonspontaneous)

The changes in Gibbs free energy of formation for Equation (3a or $3 \mathrm{~b}, 4$ and 5) were calculated based on Equation (1). The parameters of enthalpy $(\mathrm{H})$ and entropy (S) for each of the products and reactants in Equation (3a or 3b, 4 and 5) can be found from Haynes (2013):

$$
\begin{aligned}
& \left(\mathrm{NH}_{4}\right)_{2} \mathrm{SO}_{4}(\mathrm{~s}) \Rightarrow 2 \mathrm{NH}_{4}^{+}(\mathrm{aq})+\mathrm{SO}_{4}^{=}(\mathrm{aq}) \\
& \mathrm{NH}_{4} \mathrm{NO}_{3}(\mathrm{~s}) \Rightarrow \mathrm{NH}_{4}^{+}(\mathrm{aq})+\mathrm{NO}_{3}^{-}(\mathrm{aq}) \\
& \mathrm{NH}_{4}^{+}(\mathrm{aq})+\mathrm{OH}^{-}(\mathrm{aq}) \Leftrightarrow \mathrm{NH}_{3}(\mathrm{aq})+\mathrm{H}_{2} \mathrm{O}(\mathrm{l}) \\
& \mathrm{NH}_{3}(\mathrm{aq}) \Rightarrow \mathrm{NH}_{3}(\mathrm{~g})
\end{aligned}
$$

\subsection{Calculation of Equilibrium Constant of Deprotonation of Ammonium Ions IN Soil Solutions}

The spontaneous equilibrium constant of the deprotonation after fertilization was calculated according to Equation (6) (Majer et al., 2004):

$$
\mathrm{K}=\mathrm{e}^{\frac{-\Delta \mathrm{G}}{\mathrm{RT}}}
$$

where, $\Delta \mathrm{G}=$ the reaction's Gibbs free energy which is the difference between the sum of the standard Gibbs energies of the products (i.e., $\mathrm{NH}_{3}$ and $\mathrm{H}_{2} \mathrm{O}$ ) and reactants (i.e., $\mathrm{NH}_{4}^{+}$and $\mathrm{OH}^{-}$) in the reaction of deprotonation Equation (4). $\mathrm{R}$ is the gas constant (8.314 $\mathrm{J} \mathrm{K}^{-1}$ ) and $\mathrm{T}$ the absolute temperature $\left({ }^{\circ} \mathrm{K}\right)$.

\subsection{Data Analysis}

The Statistical Analysis System (SAS) version 9.1 was used for the statistical analysis. The data were analyzed by one-way ANOVA. Results were considered significant at $\mathrm{p}<0.05$. After running the SAS program, the critical ranges $\left(\mathrm{LSD}_{2,0.05}\right)$ of Duncan's Multiple Range Test were used to identify significantly different means (Hubbard, 2012).

\section{RESULTS AND DISCUSSION}

\subsection{Results}

Ammonia volatilization entails the above three steps, which occur after the application of $\mathrm{N}$ fertilizer and culminate in gaseous $\mathrm{N}$ loss via $\mathrm{NH}_{3}$ emission from agricultural soils. These three steps are as follows: (1) dissolution of the applied fertilizer in soil solution (Equation 3a or 3b); (2) deprotonation of ammonium $\left(\mathrm{NH}_{4}^{+}\right)$ions from the dissolved fertilizer (Equation 4) and (3) transformation of aqueous $\mathrm{NH}_{3}$ into gaseous $\mathrm{NH}_{3}$ (Equation 5). Each of the three steps influences the rate and extent of $\mathrm{NH}_{3}$ volatilization from agricultural soils.

Figure 1 presents the differences in Gibbs Free Energy for each of the three steps of $\mathrm{NH}_{3}$ emission from the two tested soils fertilized with ammonium sulfate and ammonium nitrate at two soil moisture regimes. Table 1 compared the equilibrium constants of depratonation of ammnium sulfate and ammonium nitrate applied to the two tested soils with $20 \%$ or $80 \%$ FC. Figure 2 shows the cumulative loss of $\mathrm{N}$ via $\mathrm{NH}_{3}$ volatilization.

\subsection{Discussion}

\subsubsection{Change in Gibbs Free Energy of the Three Steps}

The change in Gibbs free energy $(\Delta \mathrm{G})$ of step 1 (dissolution of the applied $\mathrm{NH}_{4}^{+}-\mathrm{N}$ fertilizer) was negative and small for both ammonium sources, step 2 (deprotonation of $\mathrm{NH}_{4}^{+}$ions) was negative and large, but step 3 (transformation of aqueous $\mathrm{NH}_{3}$ into gaseous $\mathrm{NH}_{3}$ ) was positive and small. Therefore, steps 1 and 2 are exergonic (proceed spontaneously); but step 3 is endergonic (does not proceed spontaneously). Accordingly, steps 1 and 2 favor $\mathrm{NH}_{3}$ volatilization, but reduce $\mathrm{N}$ use efficiency and worsen air quality. Step 2 is always the dominant driver of $\mathrm{NH}_{3}$ volatilization. Therefore, any agricultural practice intended to reduce $\mathrm{NH}_{3}$ volatilization should focus on step 2 . Thus, either the avoidance of deprotonation of $\mathrm{NH}_{4}^{+}$ions or the improvement of protonation of $\mathrm{NH}_{3}$ in the soil solution may greatly decrease the rate of step 3 and reduce net $\mathrm{NH}_{3}$ volatilization. For example, based on Equation 2 and 5, the value of $-\Delta \mathrm{G}$ becomes $90 \%$ less if the $\mathrm{pH}$ value of the soil solution is changed from 7 to 6 . Therefore, a combinational application of $\mathrm{N}$ fertilizers and physiologically acidic fertilizers, such as potassium sulfate, may greatly reduce $\mathrm{NH}_{3}$ volatilization and enhance $\mathrm{N}$ use efficiency (Dalling and Green, 1943; Hershey, 1991). 
Table 1. Equilibrium constant of deprotonation (K) of $\mathrm{NH}_{4}^{+}$leading to $\mathrm{NH}_{3}$ volatilization from either $\left(\mathrm{NH}_{4}\right)_{2} \mathrm{SO}_{4}$ or $\mathrm{NH}_{4} \mathrm{NO}_{3}$ from two soils ${ }^{\mathrm{a}}$ at either 80 or $20 \%$ Field Capacity (FC) water content

\begin{tabular}{llrr}
\hline & & Equilibrium constant, $\mathrm{K}$ \\
Soil & $\mathrm{FC}(\%)$ & $-\left(\mathrm{NH}_{4}\right)_{2} \mathrm{SO}_{4}$ & 43 \\
\hline KGL & 80 & 43 & $\mathrm{NH}_{4} \mathrm{NO}_{3}$ \\
& 20 & 131649 & 310 \\
WSL & 80 & 67 & 8 \\
& 20 & 243688 & 489 \\
\hline
\end{tabular}

${ }^{\mathrm{a}} \mathrm{KGL}=$ Krome Gravelly Loam soil; WSL $=$ Warden Silt Loam soil
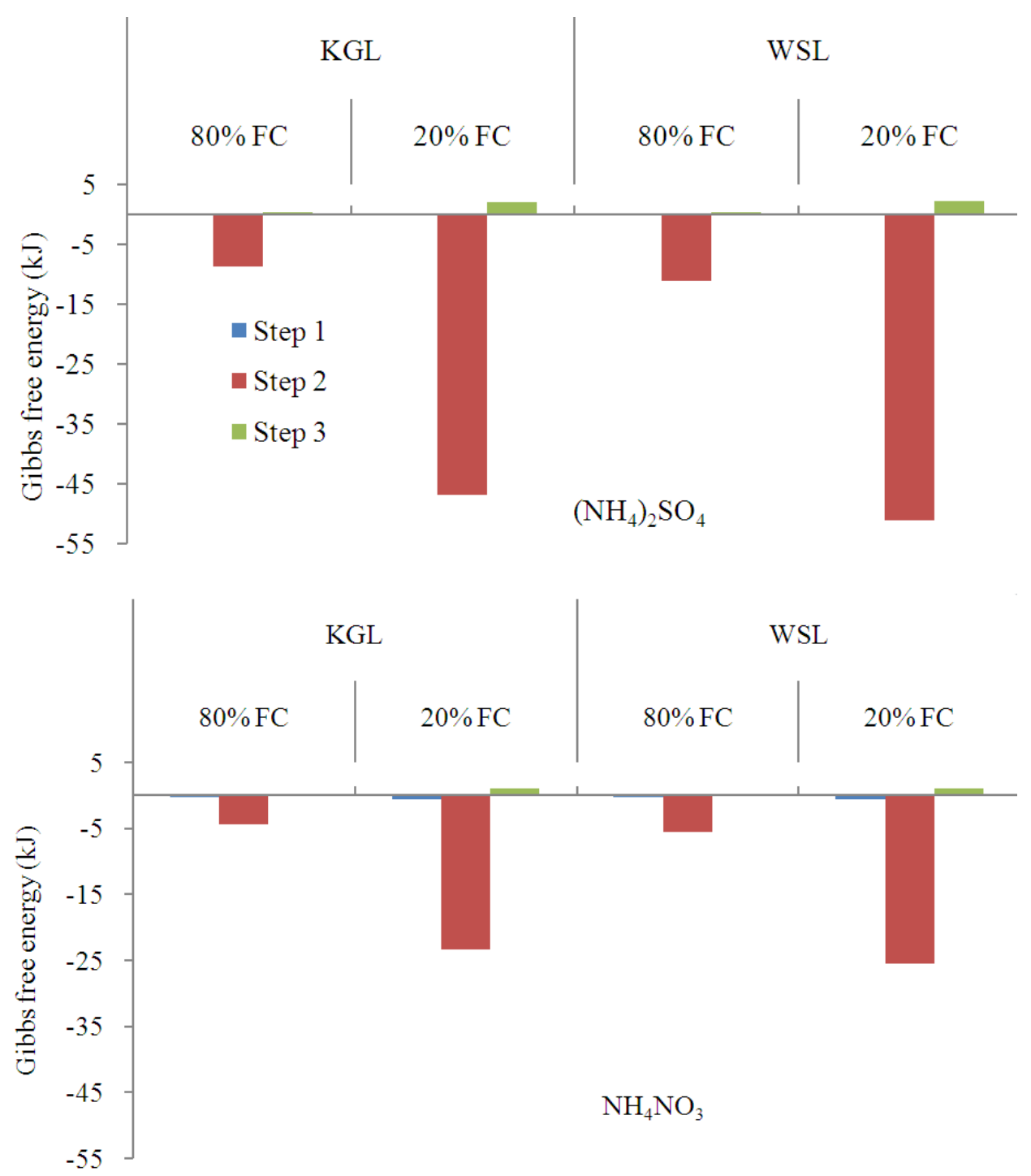

Fig. 1. Differences in Gibbs free energy ( $\Delta \mathrm{G}$, kilojoules per mole) of the 3 steps involved in ammonia volatilization from ammnium sulfate $\left[\left(\mathrm{NH}_{4}\right)_{2} \mathrm{SO}_{4}\right]$ and ammonium nitrate $\left(\mathrm{NH}_{4} \mathrm{NO}_{3}\right)$ applied to two agricultural soils at $20 \%$ and $80 \%$ Field Capacity (FC) at $20^{\circ} \mathrm{C}$. Krome Gravelly Loam (KGL) soil from Florida and Walden Silt Loam (WSL) soil from Washington State were used 


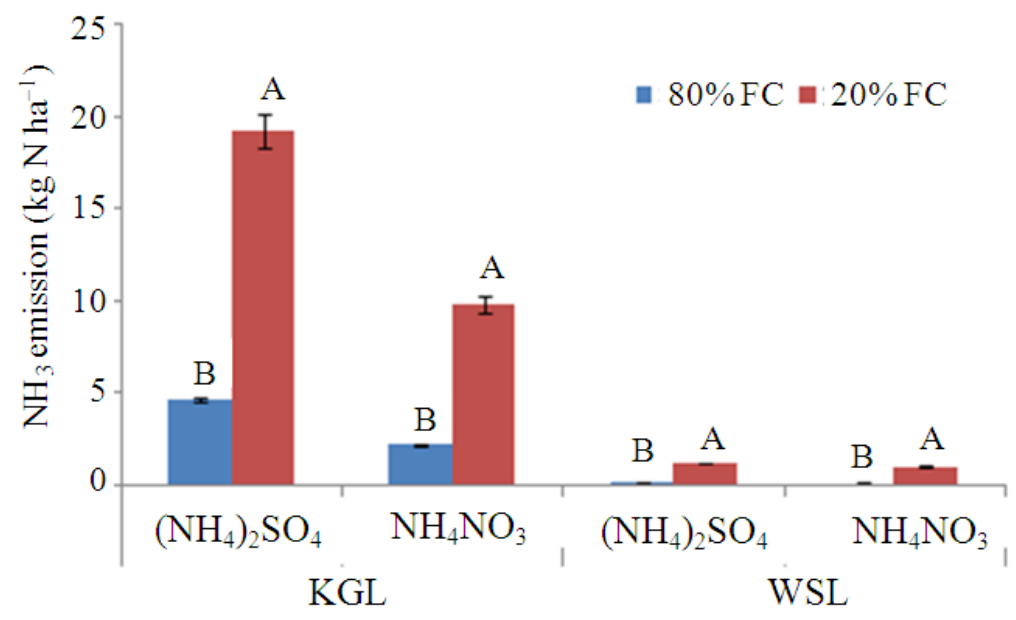

Fig. 2. Cumulative $\mathrm{N}$ loss $\left(\mathrm{kg} \mathrm{N} \mathrm{ha}^{-1}\right)$ via $\mathrm{NH}_{3}$ volatilization $\left(28 \mathrm{~d}\right.$ at $\left.20^{\circ} \mathrm{C}\right)$ from ammonium sulfate $\left.\left[\mathrm{NH}_{4}\right)_{2} \mathrm{SO}_{4}\right]$ and ammonium nitrate $\left(\mathrm{NH}_{4} \mathrm{NO}_{3}\right)$ applied to Krome Gravelly Loam (KGL) and Warden Silt Loam (WSL) soils at 80 and $20 \%$ Field Capacity (FC) soil water regimes

At $20 \%$ FC (soil drought), $-\Delta \mathrm{G}$ was always 4-to 5fold greater than that at $80 \%$ FC. This suggests that soil drought accelerated the deprotonation of $\mathrm{NH}_{4}^{+}$ions and enhanced $\mathrm{NH}_{3}$ emission from both $\mathrm{N}$ sources. Deprotonation of $\mathrm{NH}_{4}^{+}$ions is closely associated with the soil water content. In potato production systems in Florida, intermittent soil droughts occur during the growing season. Global warming may increase the frequency of occurrence of soil droughts (Sheffield and Wood, 2008). Thus, optimal water management is critical for mitigation of $\mathrm{NH}_{3}$ volatilization (Liu et al., 2007a).

Both $\left(\mathrm{NH}_{4}\right)_{2} \mathrm{SO}_{4}$ and $\mathrm{NH}_{4} \mathrm{NO}_{3}$ were applied at the same $\mathrm{N}$ rate $\left(75 \mathrm{~kg} \mathrm{ha}{ }^{-1}\right)$. However, $\left(\mathrm{NH}_{4}\right)_{2} \mathrm{SO}_{4}$ dissociates into two fold greater $\mathrm{NH}_{4}^{+}$ions than that from $\mathrm{NH}_{4} \mathrm{NO}_{3}$ (Fig. 1). Accordingly, the absolute value of $\Delta \mathrm{G}$ for $\left(\mathrm{NH}_{4}\right)_{2} \mathrm{SO}_{4}$ was twice that for $\mathrm{NH}_{4} \mathrm{NO}_{3}$. The magnitude of $-\Delta \mathrm{G}$ was dependent on $\mathrm{NH}_{4}^{+}$concentration.

\subsubsection{Equilibrium Constant $(K)$ of Deprotonation of Ammonium Ions in Soil Solutions}

The equilibrium constant $(\mathrm{K})$ of deprotonation of $\mathrm{NH}_{4}^{+}$ions were much greater than 1 across both $\mathrm{N}$ sources, soils, as well as soil water regimes (Table 1). This indicates that the deprotonation of $\mathrm{NH}_{4}^{+}$ions has a high potential across all variables in this study. The $\mathrm{K}$ values of $\left(\mathrm{NH}_{4}\right)_{2} \mathrm{SO}_{4}$ at $20 \% \mathrm{FC}$ were 3,060- and 3637 -fold greater than those at $80 \% \mathrm{FC}$, in the KGL and WSL soils, respectively. The corresponding values for $\mathrm{NH}_{4} \mathrm{NO}_{3}$ were 52-and 61-fold greater.
These data indicate that the concentration of $\mathrm{NH}_{4}^{+}$ions in the soil solution is a major factor in determining the extent of $\mathrm{NH}_{3}$ volatilization. Thus, the magnitude of $\Delta \mathrm{G}$ increased with increasing concentrations of $\mathrm{NH}_{4}^{+}$ions. Both $\mathrm{N}$ fertilizers were applied to attain a similar $\mathrm{N}$ rate $\left(75 \mathrm{~kg} \mathrm{ha}^{-1}\right)$ but the concentration of $\mathrm{NH}_{4}^{+}$ions in the soil solution of the soil which received $\left(\mathrm{NH}_{4}\right)_{2} \mathrm{SO}_{4}$ was twofold greater than that for $\mathrm{NH}_{4} \mathrm{NO}_{3}$. Thus at $20 \% \mathrm{FC}$, the $\mathrm{K}$ values of $\left(\mathrm{NH}_{4}\right)_{2} \mathrm{SO}_{4}$ was 425- and 498-fold greater than those of $\mathrm{NH}_{4} \mathrm{NO}_{3}$ in the KGL and WSL soils, respectively. The corresponding values for $80 \%$ FC were 7 -and 8 -fold. These results imply that dilution of $\mathrm{NH}_{4}^{+}$ions in the soil solution decreases the absolute value of $-\Delta \mathrm{G}$ and can, therefore, reduce $\mathrm{NH}_{3}$ volatilization.

\subsubsection{Nitrogen Loss Via Ammonia Volatilization}

Cumulative $\mathrm{NH}_{3}$ volatilization (28 d) at $20 \% \mathrm{FC}$ was 4- to 5-fold greater than that at $80 \% \mathrm{FC}$ in both soils across both $\mathrm{N}$ sources (Fig. 2). Soil droughts, which occur frequently during the growing season, in some production regions, increase the concentrations of $\mathrm{NH}_{4}^{+}$ions in soil solutions.

At the USDA Experiment Site in Paterson, WA in the Colombia River Basin, the alfalfa reference evapotranspiration reached $14 \mathrm{~mm} \mathrm{~d}^{-1}$ particularly in July and August, 2010 (Fig. 3). Under such evapotranspiration rates, soil drought develops rapidly if water management is inadequate or inappropriate. 


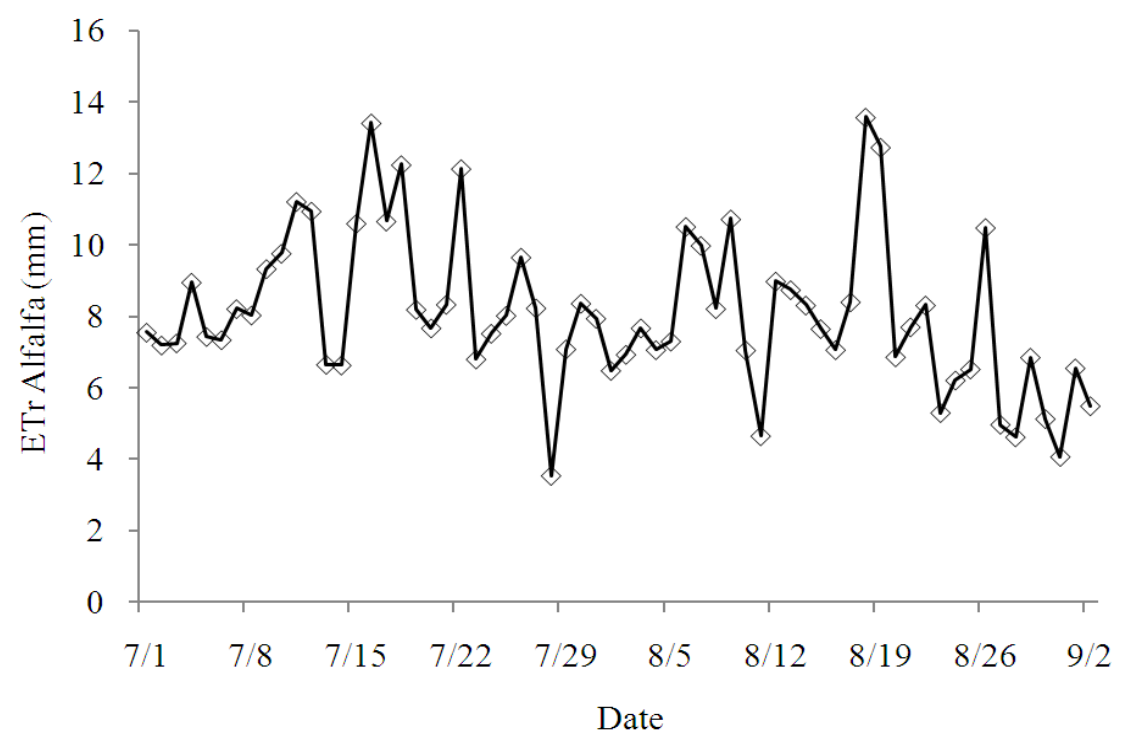

Fig. 3. Alfalfa reference evapotranspiration $\left(\mathrm{mm} \mathrm{d}^{-1}\right)$ at the USDA Experiment Site in Paterson, Washington State during July and September 2010 (http://weather.wsu.edu/awn.php)

Global warming is expected to increase evapotranspiration, reduce soil moisture (Zavaleta et al., 2003) and exacerbate the incidence of elevated soil droughts. Soil properties can also significantly affect the $\mathrm{NH}_{3}$ emissions. For example, soil acidity $(\mathrm{pH}<6.3)$ can reverse the deprotonation of $\mathrm{NH}_{4}^{+}$ions, i.e., protonate $\mathrm{NH}_{3}$ molecules to form $\mathrm{NH}_{4}^{+}$ions. This mechanism can be exploited by applying physiological acidic fertilizers with $\mathrm{NH}_{4}^{+}-\mathrm{N}$ fertilizer together to reduce $\mathrm{NH}_{3}$ volatilization from fertilized soils. Furthermore, soil particles can bind considerable amounts of $\mathrm{NH}_{4}^{+}$ions by chemical, physicochemical, or physical adsorption. In particular, a high cation exchange capacity that favors increasing $\mathrm{NH}_{4}^{+}$adsorption can prevent $\mathrm{NH}_{3}$ volatilization (Freney et al., 1981). For example, even though the $-\Delta \mathrm{G}$ for ammonium fertilizers were greater in the WSL soil than in the KGL soil, net $\mathrm{NH}_{3}$ volatilization from the former soil was less than that from the latter soil (Fig. 2). The $\mathrm{pH}$ and electrical conductivity were both lower for the WSL soil than those for the KGL soil (Liu et al., 2007b).

\section{CONCLUSION}

Ammonia volatilization from agricultural soils following the application of $\mathrm{N}$ fertilizers involves three steps: Fertilizer dissolution; deprotonation of $\mathrm{NH}_{4}^{+}$ions; and phase transformation of $\mathrm{NH}_{3}$. Among the three steps, the first two are spontaneous, i.e., $-\Delta \mathrm{G}$, while the third step is not spontaneous, i.e., $+\Delta$ G. Step 2 , deprotonation of $\mathrm{NH}_{4}^{+}$ions dominates the overall process of fertilizer dissolution leading to $\mathrm{NH}_{3}$ emission. Step 2 contributes over $95 \%$ of $-\Delta \mathrm{G}$ of the overall process which culminates in $\mathrm{NH}_{3}$ emission. The management strategies aimed to reduce $\mathrm{NH}_{3}$ volatilization should focus on delay or restriction of deprotonation of $\mathrm{NH}_{4}^{+}$ions. Soil drought greatly accelerates deprotonation and, hence, increased $\mathrm{N}$ loss via $\mathrm{NH}_{3}$ emission. The value of $-\Delta \mathrm{G}$ in the soil at $20 \%$ FC was 5-fold greater than that at $80 \%$ FC. Soil drought greatly accelerates $\mathrm{NH}_{3}$ volatilization from fertilized soils. Potential increases in temperature, a possible outcome of continued global warming, increases evapotranspiration and in turn enhances soil drought that can lead to increased $\mathrm{NH}_{3}$ volatilization from fertilized soils. Therefore, optimal soil water management is an important strategy to reduce $\mathrm{N}$ loss via $\mathrm{NH}_{3}$ volatilization from cropping systems.

\section{ACKNOWLEDGMENT}

This study was funded by USDA-ARS, specific cooperation agreement with the University of Florida. Drs. Paul W. Chun, Waldemar Klassen and Kati W. Migliaccio at the University of Florida have given constructive suggestions and comments to improve the manuscript. 


\section{REFERENCES}

Barthelmie, R.J. and S.C. Pryor, 1998. Implications of ammonia emissions for fine aerosol formation and visibility impairment: A case study from the lower Fraser Valley, British Columbia. Atmos. Environ., 32: 345-352. DOI: 10.1016/S13522310(97)83466-8

Dai, A., K.E. Trenberth and T. Qian, 2004. A global dataset of palmer drought severity index for 1870 2002: Relationship with soil moisture and effects of surface warming. J. Hydrometeorol., 5: 1117 1130. DOI: $10.1175 / \mathrm{JHM}-386.1$

Dalling, T. and H.H. Green, 1943. Trace elements in relation to health. Nature, 151: 28-31. DOI: 10.1038/151028a0

Dentener, F.J. and P.J. Crutzen, 1994. A threedimensional model of the global ammonia cycle. J. Atmo. Chem., 19: 331-369. DOI: 10.1007/BF00694492

FAO/IFA, 2001. Global estimates of Gaseous Emissions of $\mathrm{NH}_{3}$, NO and $\mathrm{N}_{2} \mathrm{O}$ from Agricultural Land. 1st Edn., International Fertilizer Industry Association, Paris, ISBN-10: 9251046891, pp: 106.

Ferm, M., 1998. Atmospheric ammonia and ammonium transport in Europe and critical loads: A review. Nutrient Cycl. Agroeco., 51: 5-17. DOI: 10.1023/A:1009780030477

Finlayson-Pitts, B.J. and J.N. Jr. Pitts, 2000. Chemistry of the Upper and Lower Atmosphere: Theory, Experiments and Applications, 1st Edn., Academic Press, San Iego, ISBN-10: 0080529070, pp: 969.

Freney, J.R., O.T. Denmead, I. Watanabe and E.T. Craswell, 1981. Ammonia and nitrous oxide losses following applications of ammonium sulfate to flooded rice. Aus. J. Agric. Res., 32: 37-45. DOI: 10.1071/AR9810037

Goyal, R.K., 2004. Sensitivity of evapotranspiration to global warming: A case study of arid zone of Rajasthan (India). Agric. Water Manage., 69: 1-11. DOI: 10.1016/j.agwat.2004.03.014

Haynes, W.M., 2013. CRC Handbook of Chemistry and Physics. 94th Edn., Taylor and Francis, Cleveland, Ohio, pp: 2668.

Hershey, D.R., 1991. Acidity and basicity of fertilizers. J. Chem. Educ., 68: 642-642. DOI: 10.1021/ed068p642

Hubbard, M.R., 2012. Statistical Quality Control for the Food Industry. 2nd Edn., Springer, Gaithersburg, ISBN-10: 1468400436, pp: 282.
IPCC, 1996. Climate Change 1995: The Science of Climate Change: Contribution of Working Group I to the Second Assessment Report of the Intergovernmental Panel on Climate Change. 1st Edn., Cambridge University Press, Cambridge, ISBN-10: 0521564360, pp: 572.

Liu, G.D., Y.C. Li and A.K. Alva, 2007a. Moisture quotients for ammonia volatilization from four soils in potato production regions. Water, Air Soil Pollu., 183: 115-127. DOI: 10.1007/s11270-007-9361-9

Liu, G.D., Y.C. Li and A.K. Alva, 2007b. Temperature quotients of ammonia emission of different nitrogen sources applied to four agricultural soils. Soil Sci. Soc. Am. J., 71: 1482-1489. DOI: 10.2136/sssaj2006.0221

Majer, V., J. Sedelbauer and R.H. Wood, 2004. Calculations of Standard Thermodynamic Properties of Aqueous Electrolytes and Nonelectrolytes, In: Aqueous Systems at Elevated Temperatures and Pressures: Physical Chemistry of Water, Palmer, D.A., R. Fernandez-Prini and A. Harvey (Eds.), Academic Press, Amsterdam, ISBN-10: 0080471994, pp: 1-4.

Martikainen, P.J., 1985. Nitrous oxide emission associated with autotrophic ammonium oxidation in coniferous forest soil. Applied Environ. Microbiol., 50: 1519-1525. PMID: 16346951

Mosier, A.R., C. Kroeze, C. Nevison, O. Oenema and S. Seitzinger et al., 1998. Closing the global $\mathrm{N}_{2} \mathrm{O}$ budget: Nitrous oxide emissions through the agricultural nitrogen cycle. Nutr. Cycl. Agroecosyst., 52: 225-248. DOI: 10.1023/A:1009740530221

Sheffield, J. and E.F. Wood, 2008. Projected changes in drought occurrence under future global warming from multi-model, multi-scenario, IPCC AR4 simulations. Climate Dynam., 31: 79-105. DOI: 10.1007/s00382-007-0340-z

Turner, D.A., R.B. Edis, D. Chen, J.R. Freney and O.T. Denmead et al., 2010. Determination and mitigation of ammonia loss from urea applied to winter wheat with N-(n-butyl) thiophosphoric triamide. Agric. Ecosyst. Environ., 137: 261-266. DOI: 10.1016/j.agee.2010.02.011

Zavaleta, E.S., B.D. Thomas, N.R. Chiariella, G.P. Ashner and M.R. Shaw et al., 2003. Plants reverse warming effect on ecosystem water balance. PNAS, 100: 9892-9893. DOI: 10.1073/pnas. 1732012100 